\title{
'L' Band Propagation Measurements for DAB Service Planning in INDIA
}

\author{
P.K.Chopra ${ }^{1}$, S. Jain ${ }^{2}$, K.M. Paul ${ }^{3}$, S. Sharma ${ }^{4}$ \\ HoD ECE ${ }^{1,2}$, Former Engineer in chief $^{3}$ \\ Ajay Kumar Garg Engineering College ${ }^{1}$, IGIT Kashmiri Gate ${ }^{2}$, All India radio ${ }^{3}$, BECIL $^{4}$ \\ Ghaziabad $^{1}$, New Delhi ${ }^{2}$ \\ India \\ prajyot_chopra@indiatimes.com,prajyotchopra@gmail.com ${ }^{1}$
}

\begin{abstract}
The nature of variations of $L$ band satellite signal strength for direct reception -both in fixed as well as in mobile reception are important technical parameters for the planning of satellite broadcast and communication services network. These parameters have been assessed through a field experiment using simulated satellite conditions. Variation of signal strength due to vegetation; urban structures; etc. as well as the building penetration loss along with the Standard Deviation of each of these variations has been assessed based on the data collected during the fixed and mobile reception. This paper gives an insight into the propagation in ' $L$ ' band under the simulated satellite conditions.
\end{abstract}

Keywords- Satellite, L-band, Signal, Mobile, Antenna, Attenuation.

\section{INTRODUCTION}

The ITU World Administrative Radio Conference-92 (WARC-92) held in Torremolinos, Spain, during February/March 1992, allocated frequency bands between 1000 and $3000 \mathrm{MHz}$ ( L Band ) to Broadcast Satellite Service(BSS)Sound and complementary Sound broadcasting. These bands are limited to the use of digital sound broadcasting. A frequency band between 1452 and $1492 \mathrm{MHz}$ was allocated on a world-wide basis, with the exception of the USA, to the Broadcast Satellite Service (BSS) and the Broadcast Service (BS) for Digital Sound Broadcasting (DSB).

Before WARC-92 there was no specific spectrum assignment available for BSS (Sound). Therefore WARC-92 represents a major milestone in the development and hence future deployment of DSB services world-wide. With the WARC-92 assignment, the efforts made for some 20 years by broadcasters, administrations, manufacturers, sound programme providers and researchers ultimately met with great success. The $1.5 \mathrm{GHz}$ frequency ( $\mathrm{L}$ band) allocation is technically close to the optimum for BSS (Sound) and complementary terrestrial services.

The world Administrative Radio Conference (WARC) organized by the ITU in Feb. 1992 interalia allocated a $40 \mathrm{MHz}$ spectrum in ' $\mathrm{L}$ ' band from 1452 to $1492 \mathrm{MHz}$ for satellite sound Broadcasting service. Report ITU-R BS.955-2 provides details of a new high quality advanced digital sound broadcasting service (Popularly termed as DAB) which could be supported through satellite in WARC' 92 allocated ' $L$ ' band spectrum for large area coverage. The DAB service is designed to provide high quality, multi-channel radio broadcasting for reception by vehicular, portable and fixed receivers. The service is rugged and yet highly spectrum efficient and consumes much lower power.

The planning of a terrestrial and satellite sound broadcasting system is strongly dependent on the factors affecting the characteristics of the propagation channel. The propagation path is subject to attenuation by shadowing due to buildings, different structurers, trees, and other foliage and to the multipath fading due to diffuse scattering from the ground and nearby obstacles such as trees and buildings. The degree of impairment to the received signal level depends on the operating frequency, the receiving antenna height, the elevation angle of the satellite and the type of environment in which the receiver is operating: whether it is an open, rural, wooded or mountainous, suburban or dense urban environment.

For moderate satellite elevation angles, it is known that over large areas (of the order of several hundred wavelengths) the mean value of field strength follows a log-normal distribution. However within small areas (of the order of a few wavelengths) two distribution models are applicable:

- Rayleigh distribution where there is no direct line-of sight (LOS) to the satellite.

The only signal is the scattered multipath signal.

- Rice distribution where there is direct line-of sight (LOS) to the satellite, giving

one component of constant amplitude as well as scattered multipath signal.

In urban areas the environment demands application of both these models. So for planning the broadcast service it is necessary to assess the nature of signal level variation in small areas under various receiving environments as stated above. 


\section{BROADCAST SERVICE PLANNING}

\section{A. Location and Time Percentage Correction Factor:}

For the planning of broadcast service with analog carrier in the VHF/UHF bands, the field strength prediction is done using ITU-R Recommendation 370 (50\% locations, 50\% time for the wanted signal and $1 \%$ time for the unwanted signal). When planning the Digital Audio Broadcasting (DAB), the same ITU-R Rec. 370 is used but with some correction factors.

In digital broadcasting, due to sharp degradation of quality when the required $\mathrm{C} / \mathrm{N}$ ratio is not obtained, calculations involving high percentage of time and locations are required for the wanted field (and low percentages for the interfering signals). Therefore an extra correction to the value derived from the ITU-R Rec. 370 curves is required. In digital broadcasting the signal availability is planned for $99 \%$ of locations, instead of 50\% in case of analog broadcasting. The correction factor for enhancement of location probability from $50 \%$ to $99 \%$ locations depends on the standard deviation (SD) of the field strength and is taken as $2.33 \mathrm{xSD} \mathrm{dB}$. This $\mathrm{SD}$ has been given in the ITU Rec. 370 as $8.3 \mathrm{~dB}$ for VHF and is appropriate for the narrow band signal as in normal analog broadcasting. However a value of $\mathrm{SD}=5.5 \mathrm{~dB}$ has been suggested in ITU-R texts as being more suitable for wideband signals like $\mathrm{DAB}$ due to a number of factors including the broadband nature of the DAB signal (COFDM modulation with $1.5 \mathrm{MHz}$ bandwidth), low receiving antenna height and use of omni-directional receiving antenna etc. Taking this value of SD (5.5dB), the correction factor for the $99 \%$ locations probability comes out to be $2.33 \times 5.5=13 \mathrm{~dB}$. Measurements in Germany and the UK indicate that still lower values of SD i.e. $3.5 \mathrm{~dB}$ and $4 \mathrm{~dB}$ on average were available. Field trials have shown that at $1.5 \mathrm{GHz}$ the same $\mathrm{SD}=5.5 \mathrm{~dB}$ can be used.

\section{However more field measurement are necessary in order to confirm the value of $\mathrm{SD}=5.5 \mathrm{~dB}$.}

It was suggested that the DAB service must be provided for 99\% time as well. ITU-R Rec.370 does not provide propagation curves for $99 \%$ time, however, for short distances the difference between 50\% time and 99\% time signal strength will be negligible and thus for convenience the existing 50\% time curves can be used.

\section{B. Receiving Antenna Height Gain Correction Factor:}

ITU-R Rec.370 curves relate to a receiving antenna height of 10 Meters above ground, whereas the DAB service will primarily be planned for mobile and portable reception, i.e. with an effective receiving antenna height of about 1.5 Meters. Measurements performed in Germany on vertically polarized Band III signals showed that an allowance of $10 \mathrm{~dB}$ is necessary to convert the field strength at 10 Meters height for use at mobile vehicle antenna height of 1.5 Meters. There are scopes to reassess this 'Antenna Height Gain Correction Factor' by further field measurements.

\section{Building Penetration Loss Factor:}

DAB services are primarily planned for vehicular reception as well as reception on portable receivers at home, without relying on fixed antennas. It follows therefore that an allowance or 'correction factor' to overcome the building penetration losses will be required in the $\mathrm{DAB}$ planning process.

Measurements within the UK in the VHF bands indicate that the median value of the building penetration loss appears to be about $8 \mathrm{~dB}$ with a standard deviation of approximately 4dB. These values are contained in ITU-R Report 1203.

In the Netherlands, the building penetration loss measurements were made at 1.5 Metres antenna height, as part of research on digital television in the UHF band at $762 \mathrm{MHz}$. The loss was measured to be approximately $7 \mathrm{~dB}$ with a low standard deviation. However, according to CCIR Report 567-4, the building penetration losses at $900 \mathrm{MHz}$, range from 10 to $25 \mathrm{~dB}$. Measurements by DBP-Telekom in Germany showed median values for penetration loss in the $500-600 \mathrm{MHz}$ range to be $13 \mathrm{~dB}$ for brick structures and $20 \mathrm{~dB}$ for concrete.

Work in the $570-670 \mathrm{MHz}$ range by the $\mathrm{BBC}$ in the UK showed the median building penetration loss value in the ground floor rooms to be $19 \mathrm{~dB}$ referenced to external measurements at 9 Meters above ground.

Building penetration loss values for L-Band are more difficult to quantify. Research on DAB in Canada showed that the median value of the loss in L-Band for an average ground floor location is $17 \mathrm{~dB}$ and that for the best ground floor location is $8.4 \mathrm{~dB}$ (ITU-R Report 1203)

Measurements made by the University of Liverpool in 1988 gave building penetration loss of between 7.5 and $15 \mathrm{~dB}$ for LBand (higher value-for Rayleigh i.e. non-LOS channel; and the lower value- for Rice or partial LOS channel). The mean value is $11.25 \mathrm{~dB}$.

In the late 1993 a number of measurements were made by the $\mathrm{BBC}$ in order to quantify the building penetration losses in L-Band (1.5MHz). From the limited no. of measurements made, a median value of $12 \mathrm{~dB}$ for the building penetration loss, at a height of about 1.5 Meters, was derived. The buildings measured were of conventional brick-built construction.

A mean of the above figures, gives a mean building penetration loss at ground floor level of $12 \mathrm{~dB}$ for L-Band.

However it is to be remembered that the building penetration loss will vary as a function of - not only its structure but also the no. of windows in the building and their size. Obviously there is a scope of further measurements of this 'building penetration loss' parameter. 


\section{L-BAND PROPAGATION MEASUREMENTS WITH 'NARROW-BAND' (CW) AND 'WIDE BAND' (COFDM) SIGNAL:}

One of the issues which comes up in the propagation measurements is to examine how different are the fade statistics for the wide band signal (COFDM), compared to that of the narrow band (CW) signal. It has been observed in many field experiments that - the low level of multipath reflections also mean that frequency diversity and/or receiver processing techniques designed to enhance reception in a frequency selective( i.e. multipath) environment are of little consequence. This leads to the conclusion that, for the environments with low multipath reflections, the narrow band $(\mathrm{CW})$ propagation measurements may also provide useful measure of the performance of wide band COFDM systems.

In the case of measurements of 'building attenuation'; 'shadow loss' or 'antenna height gain'-these are the parameters which give the difference between two figures. For example, the difference of signal levels outside and inside the building gives the 'building attenuation'; the difference of signal levels in a given environment taken without shadow and with shadow of an obstacle, gives the 'shadow loss'; similarly the difference between the field strengths measured at 10 meters antenna height and that measured at the required antenna height gives the antenna height correction factor. So these parameters being the difference signal, the effect of multipath or in other words the effect of 'wide band' signal do not make the measured parameters very much different from that of the narrow band (CW) signal.

As such as above mentioned parameters are concerned, the $\mathrm{L}$ band propagation measurements with $\mathrm{CW}$ signal give quite a fair picture of the propagation channel characteristics using broad band (COFDM) signal.

A field experiment under simulated satellite emission of CW L band signal was planned in Delhi. Through the experiment an attempt was made to assess - the building attenuation; shadow loss and antenna height gain in a CW signal environment.

\section{A. Transmitting System}

In order to simulate the satellite, a small $\mathrm{L}$ band transmitter of 3 watts power operating at $1440 \mathrm{MHz}$, along with a circularly polarized transmitting antenna was installed on the top of a high rise building (nearly 70 metres high ) in New Delhi Fig. 1. The antenna was tilted downwards in order to hit the adjoining low height buildings. The transmitting antenna used was of helical type, with a forward gain of $16.2 \mathrm{dBi}$ and Beam width of $30^{\circ}$

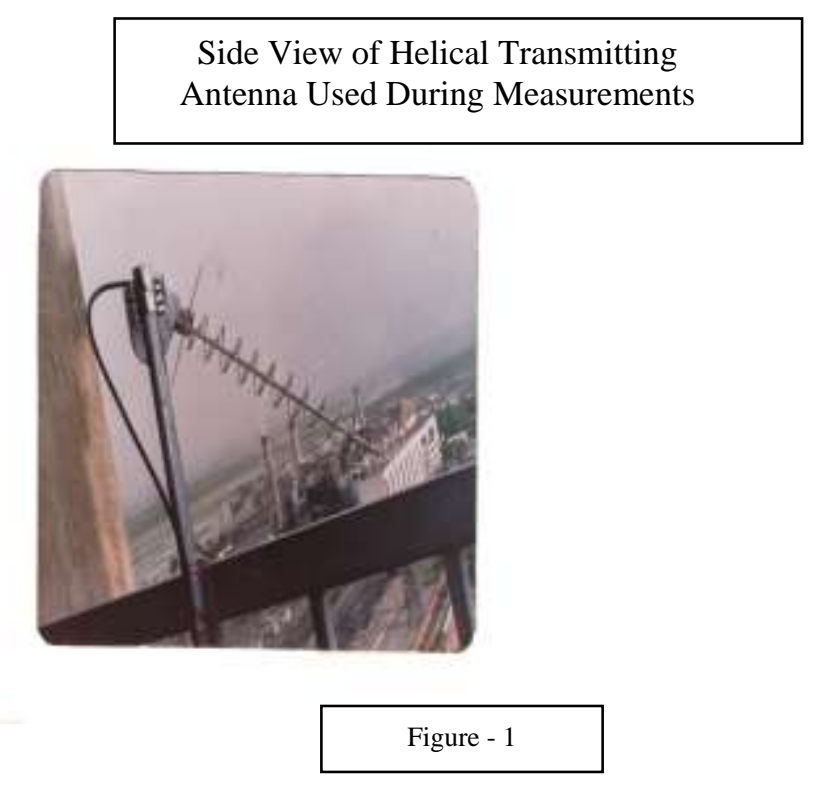

\section{B. Receiving Setup}

The receiving set up used an omni directional vertically polarized ground plane antenna having $0 \mathrm{dBd}$ gain. The signal from the receiving antenna was fed to the spectrum analyzer. The field strength values in $\mathrm{dB}(\mathrm{uv} / \mathrm{m})$ were obtained after applying the necessary antenna correction factor etc. The height of the receiving antenna was fixed at 1.5 meters above the ground for all indoor as well as outdoor measurements including mobile measurements. Provision was made to change the height of receiving antenna while investigating the variation of received signal with the height of the receiving antenna. A mobile set up in a motor vehicle equipped with spectrum analyzer and computer controlled data acquisition system was used for the experiment.

Owing to multipath, the signal varies significantly with very small distances. As such while measuring signal strength at a particular location inside the building, instead of taking a single observation, a large set of readings (49 Nos.) separated by $3 / 4$ of the wavelength (about $15 \mathrm{~cm}$ ) spread over an area of $1.05 \mathrm{mX} 1.05 \mathrm{~m}$ were taken and the average value worked out corresponding to each site. Fig.2 provides a sample of fluctuations of field strength at $1440 \mathrm{MHz}$ within the small area. 


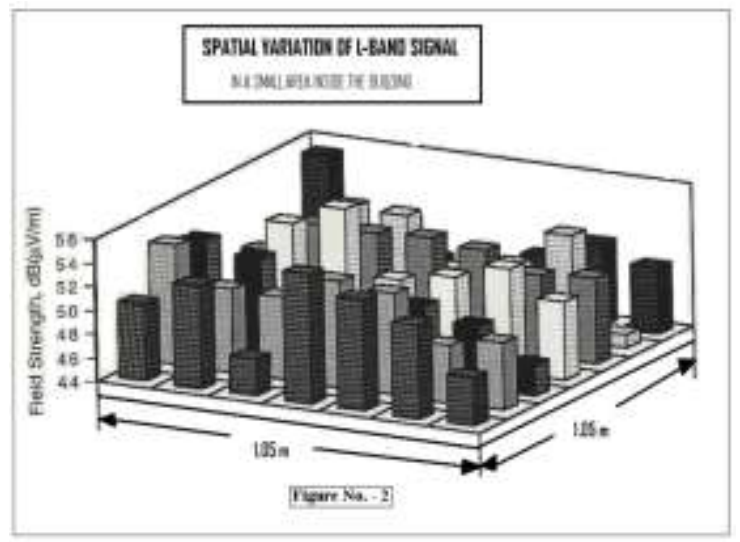

While measuring the building attenuation, the locations inside the building have been divided into three types - 'Best Locations'; 'Average Locations' and 'Worst Locations'. The Best Locations are sites very close to the doors/windows on the outer building wall facing the transmitter. The 'Average Locations' are the sites inside the building which are slightly inside the building and away from the 'Best Locations'. The third type is the 'Worst Locations'. These are the sites deep inside the building and obstructed from transmitter by multiple attenuating walls.

\section{Measurement of Building Attenuation}

To ascertain the amount of attenuation of L-Band signal inside multistoried concrete buildings, a set of measurement were planned. Three typical buildings in near vicinity of the transmitting site were selected for the purpose. The transmitting antenna was made to direct towards the middle floor of the building selected for measurements. A set of measurements were carried out at the First building which is a 6 storied cement concrete building. The transmitter was making an elevation angle of 32 degrees from the measuring site at the building. In case of the Second and Third buildings the similar elevation of the transmitter from the respective measuring sites were 38.9 degrees and 47.7 degrees respectively. The sample of ' $\mathrm{L}$ ' band field strength measurements taken at ground floor of a multistoried building is given in Annexure 1.

\section{Measurement of Shadow Loss}

A set of field strength measurement were taken in direct line of sight and in various shadow conditions of the buildings to evaluate shadow losses encountered in typical urban environment. These measurements were taken with the help of the Mobile set up, by moving the vehicle at a very slow speed (3-5 km/hour). A sample of field strength variation measured during the experiment is given in Fig.3. The receiving antenna was mounted on the rear side of the vehicle at a height of $1.5 \mathrm{~m}$ from the ground. Continuous field strength recordings were made for line of sight as well as for the shadow areas as encountered on the way. The measurements can be classified into the following three types. a) Measuring points in direct line of sight of the transmitting antenna.

b) Measuring points located in the shadow of a multistoried building with large open area behind (no reflecting structures).

c) Measuring points located in Narrow Street between multistoried concrete buildings.

\section{E. Field Strength Measurement with Variation of Receiving Antenna Height}

In order to determine the variation of field strength with height of the receiving antenna above the ground, the field strengths were measured at a fixed location by lowering the receiving antenna from $8 \mathrm{~m}$ to $1.5 \mathrm{~m}$. Measurements were made in direct line-of-sight as well as in obstructed visibility.

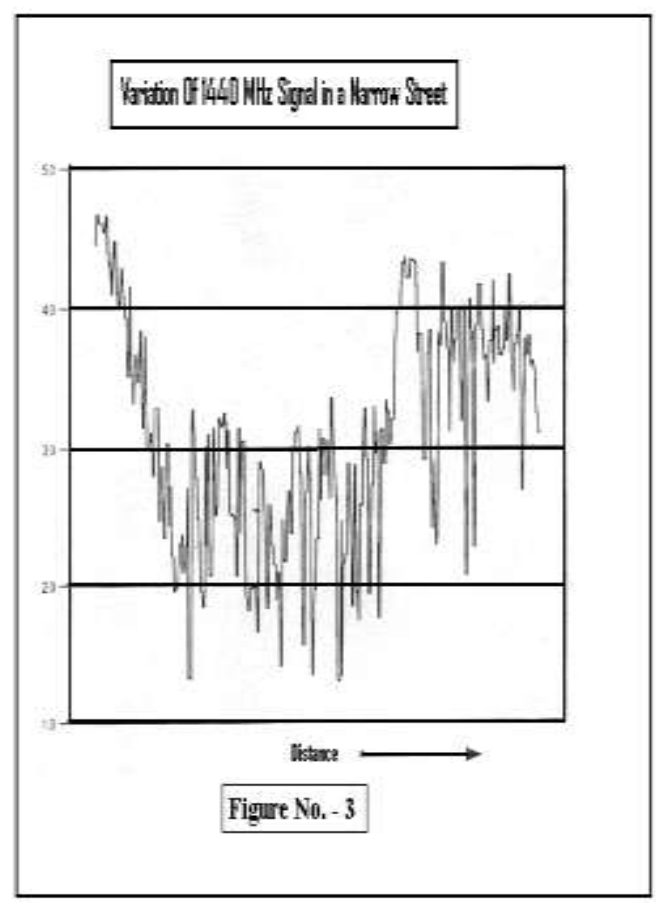

\section{ANALYSIS OF DATA}

In order to assess building attenuation, the field strength values measured inside the building at each floor for various sites were compared with the respective line-of -sight values measured outside the windows. Thus, for each building and floor, building attenuation was worked out in $\mathrm{dB}$ as given in Table-1.

The building attenuations for 'Best', 'Average' and 'Worst' sites were found to be 7.4 to $15.5 \mathrm{~dB} ; 9.5$ to $19.0 \mathrm{~dB}$ and 14.0 to $24.9 \mathrm{~dB}$ respectively with a standard deviation in the range of 3 to $5 \mathrm{~dB}$. 
For assessment of shadow losses, the predicted field strength for free space propagation for various measuring conditions were calculated. Different percentile values of the measured field strengths relative to their respective predicted free space values were plotted. Fig. 4 (a) \& 4 (b) show the statistical distribution of the relative field strengths in various environmental conditions. The shadow loss in $\mathrm{dB}$ was obtained by comparing the relative field strength values of direct line-ofsight with those obtained in shadow areas. The shadow loss of multistoried building with large open area behind was found to be $21 \mathrm{~dB}$ for an elevation angle of $26^{\circ}$. The shadow loss of multistoried buildings in Narrow street in typical urban environment was found to be $12 \mathrm{~dB}$ for average elevation angle of $42^{0}$.

Fig.5 provides the fluctuation of the field strength as a function of the receiving antenna height at a fixed point in direct line of sight as well as in obstructed visibility. The field strengths have been expressed relative to the predicted field strength for free space propagation.

\section{CONCLUSION}

The present study provides some insight into the radio wave propagation in ' $\mathrm{L}$ ' band under the simulated satellite conditions. The attenuation inside multistoried buildings was found to vary from 7.4 to $15.5 \mathrm{~dB}$ for 'Best' locations and from 14.0 to $24.9 \mathrm{~dB}$ for 'Worst' locations. The shadow loss of multistoried buildings with open fields behind was found to be $21 \mathrm{~dB}$ whereas in Narrow Street between multistoried buildings it was found to be $12 \mathrm{~dB}$. The received field strength was also found to be fluctuating around its mean value with the variation of receiving antenna height. The fluctuation was more prominent in shadow area as compared to direct line of sight conditions.

\section{ACKNOWLEDGEMENT}

I sincerely thank UNIVERSITY SCHOOL OF ENGINEERING \& TECHNOLOGY, Guru Govind Singh Indraprastha University, New Delhi for providing the opportunity and guidance for research work.

\section{REFERENCES}

[1] ITU-R special publication on "Terrestrial and satellite digital sound broadcasting to Vehicular, portable and fixed receivers in the VHF/UHF bands", Radio communication Bureau, Geneva, 1995.

[2] Butt, G., Evans, B.G. Richharia, M.: "Narrowband channel statistics from multiband propagation measurement applicable to High Elevation Angle land mobile satellite Systems", IEEE journal on selected areas in communications, vol 10, no, 8, Ocotber, 1992, pp.1219-1226

[3] Goldhrish, J. Vogel, W.J.: "Mobile Satellite system Fade Statistics for Shadowing and Multipath from Roadside Trees at UHF and L-band", IEE Transactions on Antennas \& propagation, vol. 37, no. 4 April, 1989, pp 489-498

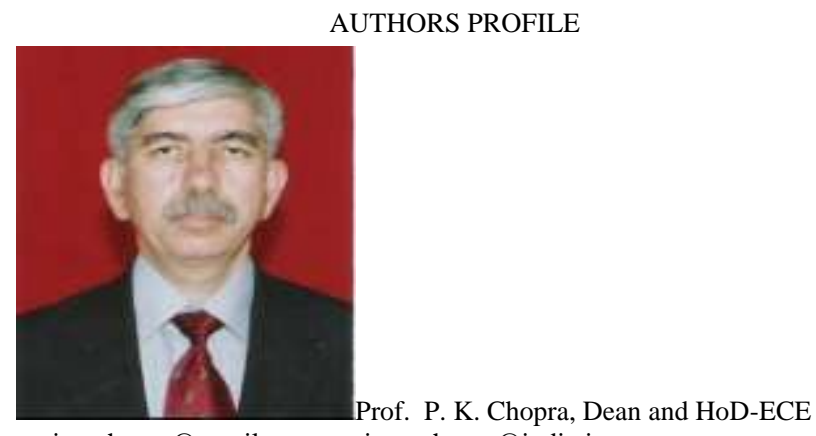

prajyotchopra@gmail.com, prajyot_chopra@indiatimes.com

AJAY KUMAR GARG ENGINEERING COLLEGE, GHAZIABAD, U.P. (India)

Prof. Pradeep Kumar Chopra entered the field of education in the year 2004 after 24 years of exemplary service in the technical branch of the Indian Air Force, He earned his Bachelors degree in Engineering (Electronics) from Delhi college of Engineering in the year 1979 and Masters in Technology from IIT Delhi in the year 1985. He also has a Masters degree in Defence Studies from Madras University. While he was in the Indian Air Force he was part of, and headed a number of important technical projects. For his exemplary services he was awarded "Vishist Seva Medal" by the President of India in the year 1993. He took premature retirement from the IAF in the year 2004 and entered the field of education. He is the Dean and Head of Dept. (Electronics and Communication) in Ajay Kumar Garg Engineering College in Ghaziabad. AKGEC is rated as the No 1 Engineering Colleges in U.P. (India) affiliated to Uttar Pradesh Technical University, Lucknow (U.P.) India. 

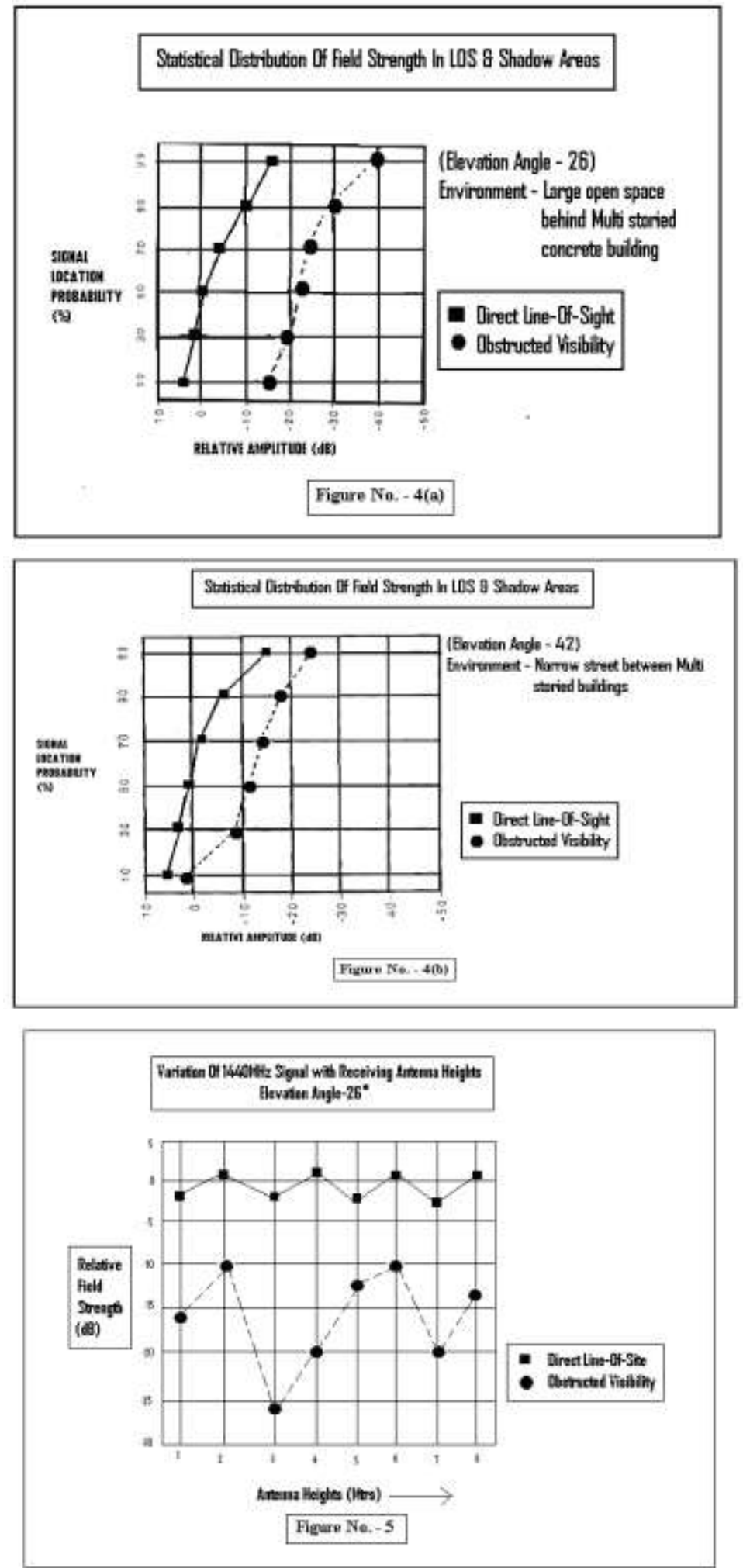

http://ijacsa.thesai.org/ 


\section{$\underline{\text { TABLE - } 1}$}

Building Attenuation in dB

\begin{tabular}{|c|c|c|c|c|c|}
\hline \multirow[t]{2}{*}{ Sl. No. } & \multirow{2}{*}{$\begin{array}{l}\text { Name of Building/ } \\
\text { Elevation Angle }\end{array}$} & \multirow[t]{2}{*}{ Floor } & \multicolumn{3}{|c|}{ Building Attenuation (dB) } \\
\hline & & & Best Location & $\begin{array}{l}\text { Average } \\
\text { location }\end{array}$ & $\begin{array}{c}\text { Worst } \\
\text { location }\end{array}$ \\
\hline 1. & Y-Shape/32 ${ }^{\circ}$ & $\begin{array}{c}\text { Ground } \\
\mathbf{1}^{\text {st }} \\
2^{\text {nd }} \\
3^{\text {rd }} \\
4^{\text {th }} \\
5^{\text {th }}\end{array}$ & \begin{tabular}{|c|}
15.5 \\
7.4 \\
10.2 \\
7.8 \\
12.8 \\
13.0
\end{tabular} & $\begin{array}{l}16.0 \\
14.2 \\
14.5 \\
16.1 \\
18.9 \\
19.0\end{array}$ & $\begin{array}{l}24.9 \\
23.6 \\
20.2 \\
19.4 \\
23.0 \\
24.9\end{array}$ \\
\hline 2. & SPA $/ 38.9^{\circ}$ & $\begin{array}{c}\text { Ground } \\
1^{\text {st }} \\
2^{\text {nd }} \\
3^{\text {rd }}\end{array}$ & $\begin{array}{c}12.2 \\
7.6 \\
8.4 \\
10.1\end{array}$ & $\begin{array}{c}15.5 \\
- \\
9.5 \\
12.8\end{array}$ & $\begin{array}{l}17.9 \\
18.0 \\
14.0 \\
16.7\end{array}$ \\
\hline 3. & $\mathrm{AVM} / 47.7^{\circ}$ & $\begin{array}{l}\text { Ground } \\
1^{\text {st }}\end{array}$ & $\begin{array}{c}10.6 \\
9.9\end{array}$ & $\begin{array}{l}16.7 \\
14.4\end{array}$ & $\begin{array}{l}20.4 \\
14.3\end{array}$ \\
\hline
\end{tabular}

\section{$\underline{\text { ANNEXURE - } 1}$}

\section{SAMPLE OF 'L' BAND FIELD STRENGTH MEASUREMENTS TAKEN AT GROUND FLOOR OF A} MULTISTORIED BUILDING

“05-04-2010","”,"AT AVM - GW1", "\# “, 1

"START TIME=","16:28:02","STOP TIME=","16:28:04","ON STATIONARY VEHI

"AVERAGE SIGNAL=", 25.94333," dBUV / M","STD.DEV.=", .5938197,"dBUV / M" 25.85,25.5,25.5,25.5,25.5,26.05,26.05,26.05,27.05,27.05,27.05,25.5,25

“05-04-2010","”,"AT AVM - GW1", "\# ", 2

"START TIME=","16:28:43","STOP TIME=","16:28:46","ON STATIONARY VEHI

"AVERAGE SIGNAL=", 23.73667," dBUV / M","STD.DEV . =", .7605847,"dBUV / M" 24.35, 24.35, 24.3, 24.3, 24.3, 24.3, 24.65, 24.65, 22.55, 22.55, 22.55, 23.3,23

\begin{tabular}{|c|}
\hline $\begin{array}{l}\text { “05-04-2010",",",AT AVM - GW1", "\# ", } 3 \\
\text { "START TIME=","16:29:09","STOP TIME=","16:29:11","ON STATIONARY VEHI } \\
\text { "AVERAGE SIGNAL=", 28.98," dBUV / M","STD.DEV.=", .4925444,"dBUV / M" } \\
\text { 29.5,29.5,29.5,29.5,28.4,28.4,28.4,28.4,29.65,29.65,28.7,28.7,28.7,28 }\end{array}$ \\
\hline $\begin{array}{l}\text { “05-04-2010","," "AT AVM - GW1", “\# “, } 4 \\
\text { "START TIME=","16:29:36","STOP TIME=","16:29:38","ON STATIONARY VEHI } \\
\text { "AVERAGE SIGNAL=", 25.53333," dBUV / M","STD.DEV. =", .2958977,"dBUV / M" } \\
\text { 25.65, 25.65, 25.8, 25.8, 25.8, 25.8, 25.05, 25.05, 25.25, 25.25, 25.25, 25.25, } 25\end{array}$ \\
\hline $\begin{array}{l}\text { “05-04-2010",",",AT AVM - GW1", “\# “, } 5 \\
\text { "START TIME=","16:30:21","STOP TIME=","16:30:23","ON STATIONARY VEHI } \\
\text { "AVERAGE SIGNAL=", 16.25," dBUV / M","STD.DEV.=", .7722261,"dBUV / M" } \\
\text { 15.05, 15.05, 15.05, 15.05, 16.6, 16.6, 16.6, 16.6, 16.9, 16.9, 16.45, 16.45, 16. }\end{array}$ \\
\hline
\end{tabular}

“05-04-2010",",", AT AVM - GW1", “\# ", 6 
"START TIME=","16:30:47","STOP TIME=","16:30:49","ON STATIONARY VEHI "AVERAGE SIGNAL=", 23.99333," dBUV / M","STD.DEV . =", .6096078,"dBUV / M" 24.4, 24.4, 24.4, 23.2, 23.2, 23.2, 23.2, 23.4, 23.4, 24.65, 24.65, 24.65, 24.65, 24

\begin{tabular}{|c|}
\hline 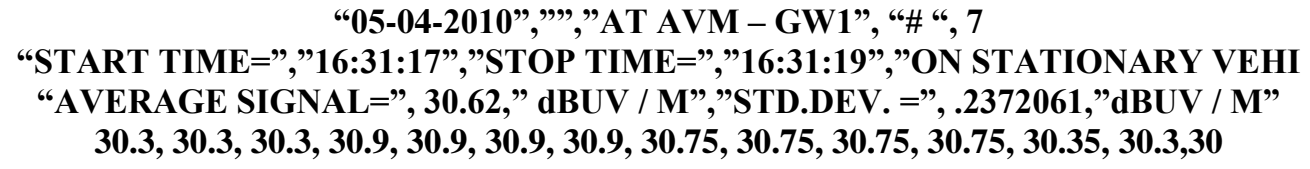 \\
\hline $\begin{array}{l}\text { “05-04-2010",",",AT AVM - GW1", “\# ", } 8 \\
\text { “START TIME=","16:31:36","STOP TIME=","16:31:38","ON STATIONARY VEHI } \\
\text { “AVERAGE SIGNAL=", 30.71," dBUV / M","STD.DEV.=", .3791219,"dBUV / M" } \\
\text { 30.3, 30.25, 30.25, 30.25, 30.25, 30.65, 30.65, 30.65, 30.65, 31, 31, 31, 31.25, 31 }\end{array}$ \\
\hline $\begin{array}{l}\text { “05-04-2010",",",AT AVM - GW1", “\# ", } 9 \\
\text { "START TIME=","16:32:02","STOP TIME=","16:32:04","'ON STATIONARY VEHI } \\
\text { "AVERAGE SIGNAL=", 23.16667," dBUV / M","STD.DEV.=", .7196444,"dBUV / M" } \\
\text { 23.05, 23.05, 23.05, 23.05, 22.45, 22.45, 22.45, 22.45, 24.3, 24.3, 24.3, 24.3, } 24\end{array}$ \\
\hline
\end{tabular}

“05-04-2010",",,"AT AVM - GW1", “\# ", 10

"START TIME=","16:32:17","STOP TIME=","16:32:20","ON STATIONARY VEHI

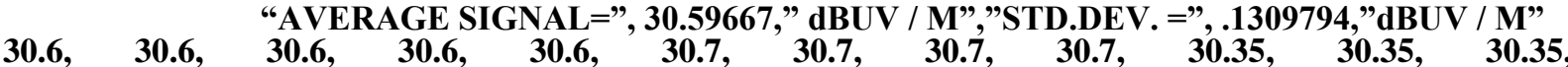

